\title{
Chronic pancreatitis in children: treat like an adult?
}

\author{
Miguel Paiva Pereira ำ ${ }^{1}$ Filipa Santos, ${ }^{2}$ Ana Serrão Neto, ${ }^{3}$ Jorge Canena ${ }^{4}$
}

${ }^{1}$ Hospital CUF Descobertas, Lisboa, Portugal

${ }^{2}$ Hospital CUF Descobertas, Lisboa, Portugal

${ }^{3}$ Centro da Criança e do Adolescente, Hospital CUF Descobertas, Lisboa, Portugal ${ }^{4}$ CUF, Lisboa, Portugal

\section{Correspondence to} Dr Miguel Paiva Pereira; miguelpereira2112@gmail.com

Accepted 12 October 2019

Check for updates

(c) BMJ Publishing Group Limited 2019. No commercial re-use. See rights and permissions. Published by BMJ.

To cite: Pereira MP, Santos $F_{\text {, }}$ Neto AS, et al. BMJ Case Rep 2019;0. doi:10.1136/bcr$2019-231714$

\section{SUMMARY}

A 15-year-old boy with a medical background of obesity, familial hyperlipidemia and acute recurrent pancreatitis, presented to emergency department reporting a 3-day course of periumbilical abdominal pain and nausea. Pain was noticed on epigastric palpation. Laboratory evaluation revealed leucocytosis, neutrophilia and pancreatic enzymes elevation more than three times the upper limit of normal. An acute recurrence of pancreatitis was diagnosed, was admitted to the hospital, being discharged after 5 days. Four days after, he was readmitted because of symptoms recurrence. Elevation of transaminases, GGT and direct bilirubin were noticed. Pancreatic enzymes still elevated but lower than in the previous episode. An endoscopic ultrasound revealed a Wirsung with a cephalic stricture and diffuse structural abnormalities suggestive of chronic pancreatitis. The patients was submitted to endotherapy with several sessions of endoscopic retrograde cholangiopancreatography including stenting and pancreatoscopy with marked clinical and imaging improvement. A genetic variant was identified.

\section{BACKGROUND}

Although chronic pancreatitis (CP) is a rare disease in children and adolescents, it has an important disease burden and a negative impact in quality of life. Given the rarity of the diagnosis, all cases of $\mathrm{CP}$ in paediatric age represent learning opportunities. This case shows the importance of a multidisciplinary team in the management of patients with $\mathrm{CP}$ to ensure optimal outcomes and reinforces the value of a genetic analyses when no other cause is found for the disease.

\section{CASE PRESENTATION}

A 15 -year-old adolescent boy presented to a paediatric emergency department (ED) reporting a 3-day course of periumbilical abdominal pain, accompanied by general malaise and nausea, without vomiting. The patient was obese, with history of familial type IV hyperlipidemia (Fredrickson's) phenotype and acute recurrent pancreatitis (ARP) (five episodes beginning at age 11 years, having undergone multiple abdominal ultrasounds, an upper gastrointestinal endoscopy, an abdominal CT, a magnetic resonance cholangiopancreatography (MRCP), investigation of celiac disease, cystic fibrosis, autoimmune diseases and other etiological studies, without identification of the cause). Between the acute episodes, nutritional support was provided to the patient. Family history was positive for obesity (both parents), asthma and celiac disease (mother), and type II diabetes, dyslipidemia and early cardiovascular disease (maternal family). The patient has a healthy older sister.

On examination, the patient had skin pallor, tachycardia and pain was elicited on epigastric palpation. No fever, jaundice, hepatosplenomegaly or active bleeding was observed.

Blood tests were performed and revealed leucocytosis, neutrophilia and elevation of amylase 16 times the upper limit of normal (ULN) (1750 U/L) and lipase 53 times the ULN (11550 U/L). The serum calcium, liver enzymes and bilirubin were normal. Total cholesterol $(188 \mathrm{mg} / \mathrm{dL})$, LDL cholesterol $(119 \mathrm{mg} / \mathrm{dL})$ and triglycerides $(178 \mathrm{mg} / \mathrm{dL})$ were slightly elevated. An abdominal ultrasound was performed but no clear image of the pancreas was obtained because of gas interference. An acute recurrence of pancreatitis was diagnosed, and he was admitted to the hospital with no oral intake and was kept on intravenous hydration and analgesia. By the fifth day from admission, clinical improvement and stability were noteworthy so he was discharged and scheduled a follow-up appointment with a gastroenterologist. Four days after discharge, he returned to the same paediatric ED due to recurrence of nausea and abdominal pain, associated with jaundice and coluria. Analytically, elevation of transaminases, GGT and direct bilirubin, with a clear decrease of pancreatic enzymes in relation to the previous episode. An abdominal ultrasound was performed, showing a gallbladder with a $5 \mathrm{~mm}$ parietal thickening, not distended, with thick bile, with no signs of lithiasis and a Wirsung channel with $3 \mathrm{~mm}$ calibre. The patient was admitted and started on intravenous analgesia and hydration. $\mathrm{He}$ clinically improved and was discharged after 6 days. A multidisciplinary meeting was held (paediatrics, paediatric and adult gastroenterology, surgery and radiology), and it was decided to perform an endoscopic ultrasound in the outpatient setting.

\section{INVESTIGATIONS}

An endoscopic ultrasound was performed 1 month after discharge and revealed diffuse structural abnormalities throughout the pancreas suggestive of $\mathrm{CP}$, more evident in the cephalic region, with a lobular pattern, bands and hyperechogenic foci, and also a small parenchymal calcification in the head of the pancreas; the Wirsung showed an irregular calibre, with a stenosis in the cephalic region and marked echogenicity of the wall compatible with periductal fibrosis; a pseudocyst $(17 \times 14 \mathrm{~mm})$ was found adjacent to the body-tail transition of the pancreas. Biopsies showed mild non-specific duodenitis, chronic atrophic gastritis with mild 


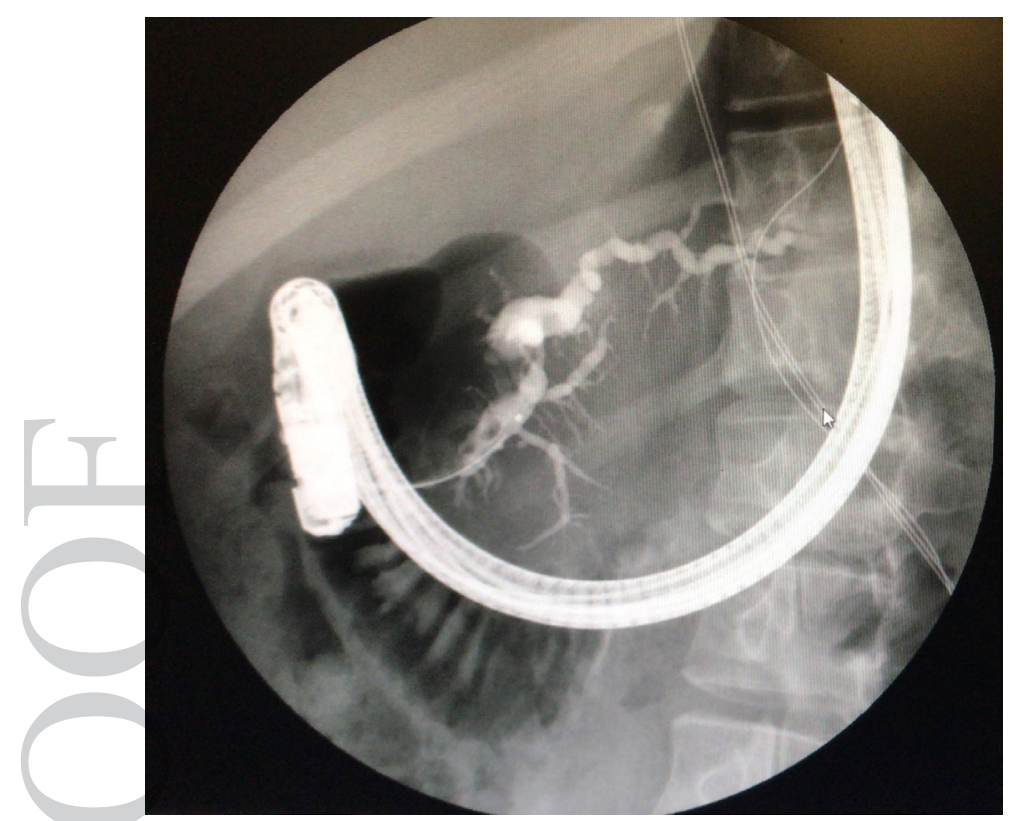

Figure 1 Pancreatogram showing distortion of the Wirsung with a major cephalic stricture, body dilatation and minor strictures of the tail. Intraductal lithiasis can be noted.

activity and focal intestinal metaplasia and foveolar hyperplasia, consistent with reactive gastropathy.

An endoscopic retrograde cholangiopancreatography (ERCP) performed 3 months after discharge confirmed features suggestive of CP with multiple Wirsung stenoses, conditioning dilatation and eventual intraductal lithiasis (figure 1).

In the genetic study, no recognised pathogenic variants were identified in the genes analysed. A variant was identified in the CFTR gene c.2991G >C (p.Leu997Phe).

\section{DIFFERENTIAL DIAGNOSIS}

Following the INternational Study Group of Pediatric Pancreatitis: In search for a cuRE (INSPPIRE) criteria, this is a case of $\mathrm{CP}$ since the patient has pancreatic duct abnormalities together with some periods of consistent abdominal pain and lipase or amylase elevation.

Despite being a known risk factor for CP, the hypertriglyceridemia in this case does not seem to be the main reason since during the acute episodes, the patient usually has normal to slightly elevated triglycerides and LDL cholesterol levels. Accordingly to this hypothesis, a genetic study was run and identified a variant in one of the genes whose mutations are associated with a higher risk of CP.

Even though the interpretation of pathogenesis of this CFTR variant is still conflicting (clinical significance uncertain or probably pathogenic), bioinformatically it is predicted to be deleterious.

We hypothesised that the pancreatic duct stenoses were probably the result of a cicatricial process due to the various exacerbations of ARP, considering that such alterations were not noticed in previous ultrasounds and MRCP's. In this case, $\mathrm{CP}$ was the result of sequelae changes in the Wirsung duct resulting from recurrent acute pancreatitis (AP), which in this case has a multifactorial aetiology with a genetic predisposition associated with risk factors such as obesity and hypertriglyceridemia.

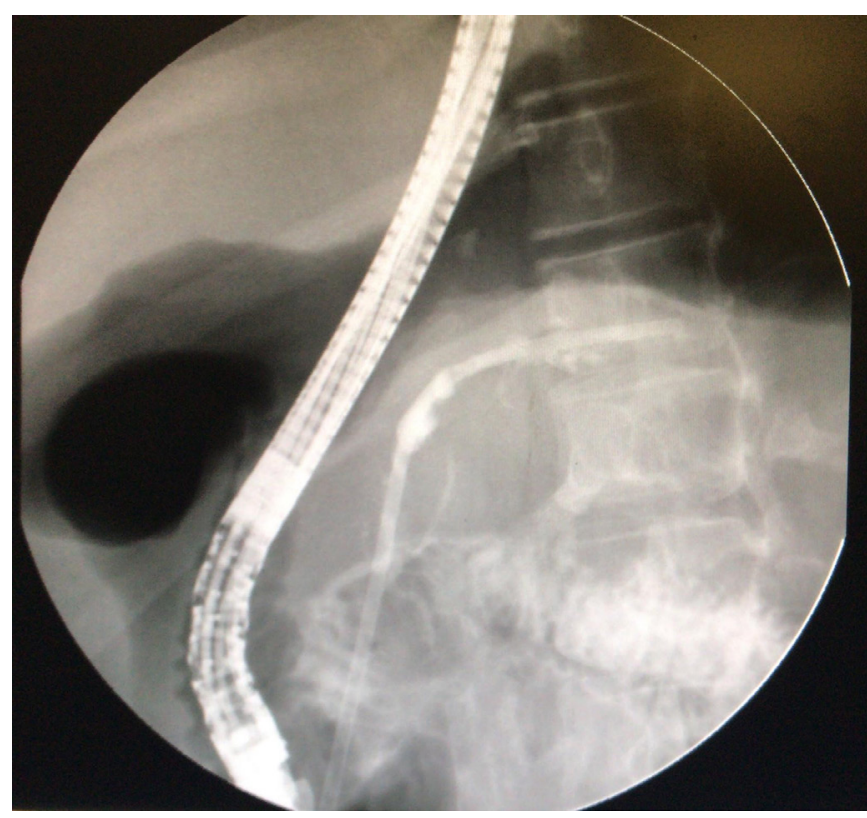

Figure 2 Fluoroscopic image of the Wirsung showing a 10Fr stent in place from the head to the tail of the pancreas.

\section{TREATMENT}

The patient underwent five sessions of therapeutic ERCPs between May and November with placement of an increasing number of plastic stents after dilation with a balloon of the pancreatic stenosis. During the ERCP procedures, the patient was submitted to pancreatoscopy which helped to confirm the presence of small intraductal stones which were removed by a dormia basket. Furthemore, the pancreatoscope allowed successful placement of a guidewire across the tail strictures (figures 2-6).

The patient was also started on pancreatin $150 \mathrm{mg} 2 \mathrm{id}$ (lunch and dinner), and nutritional support.

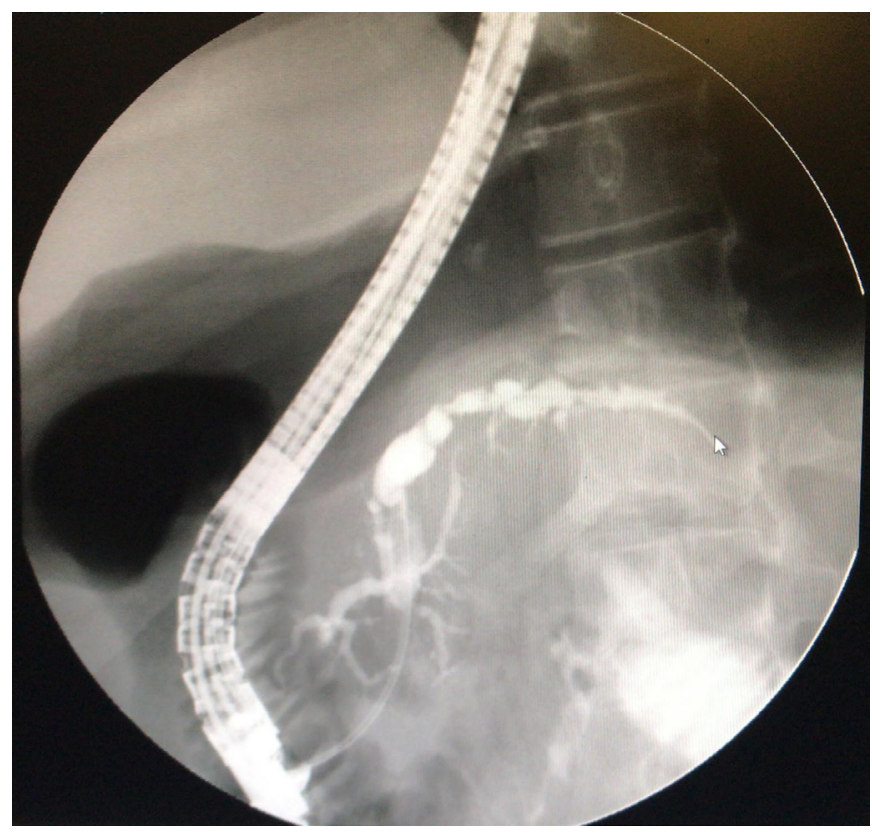

Figure 3 Wirsungography showing a marked radiological improvement after five sessions of endotherapy. 


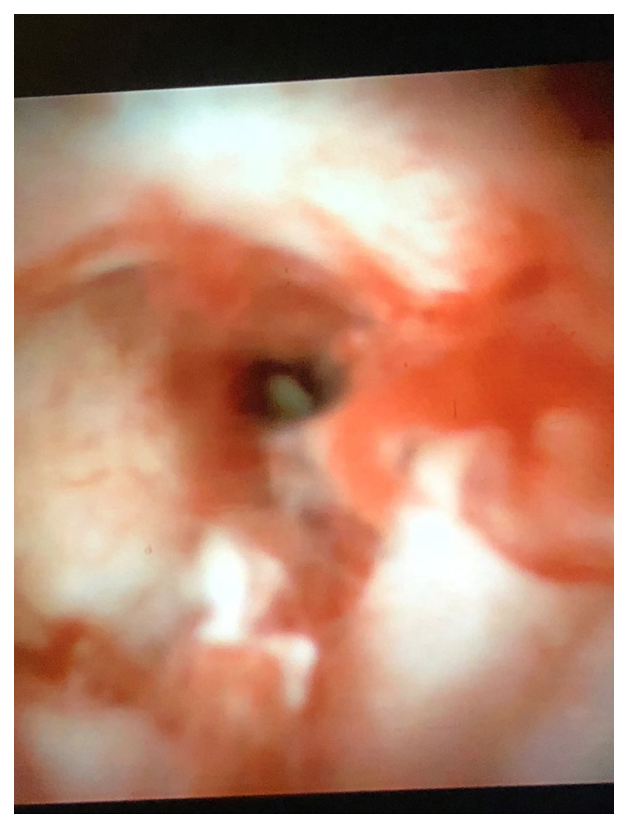

Figure 4 Image of pancreatoscopy of the pancreatic head where a stricture and new vascularisation due to chronic inflammation can be noted.

\section{OUTCOME AND FOLLOW-UP}

The patient improved clinically after the therapeutic interventions, being currently without nausea and without the general malaise that he felt for several years sometimes on a daily basis.

During the last procedure, there was a clear improvement of the cephalic stenoses, still with stenosis in the middle portion of the body and a closed stenosis in the body-tail transition, unconstrained by the wire. A new ERCP has been scheduled within 4 months and these interventions are planned to be stopped after 15 months of endoscopic treatment.

He maintains the usual follow-up with the general paediatrician and paediatric gastroenterology, and is expected to

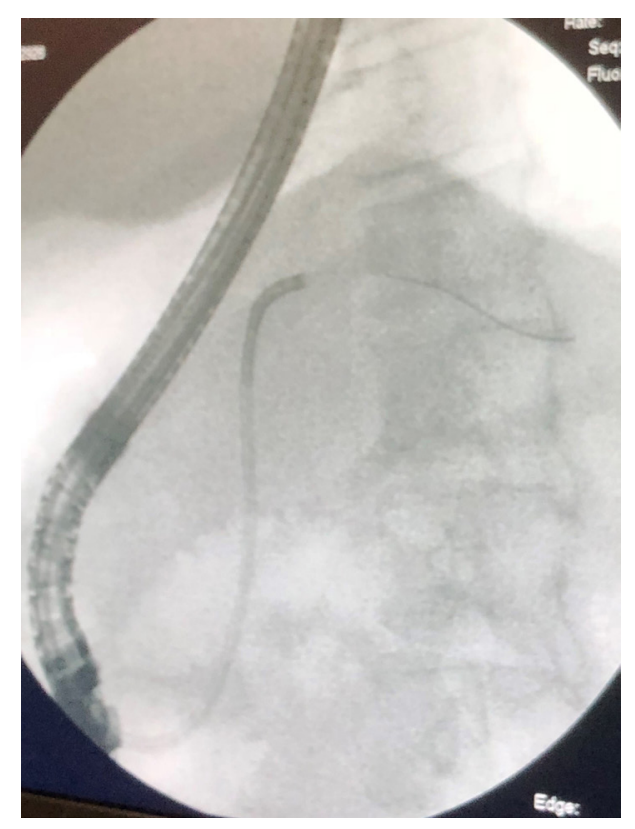

Figure 5 Fluoroscopic image of a pancreatoscope in the Wirsung allowing the placement of a guidewire under direct visualisation.

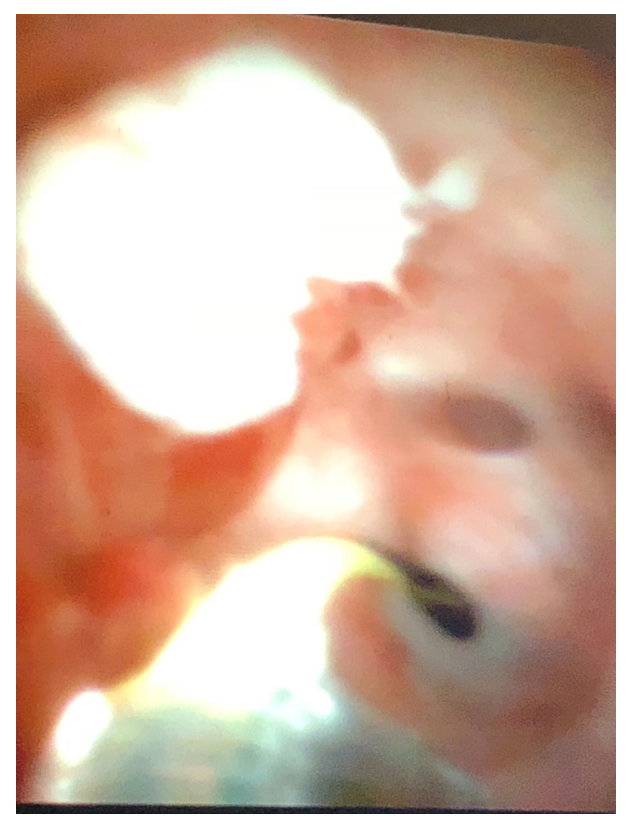

Figure 6 Image of pancreatoscopy of the tail, in which a stone and correct placement of the guidewire can be seen.

progressively transit to adult gastroenterology in the coming years, in order to ensure clinical stability in the future.

\section{DISCUSSION}

This patient had the first episode of AP at age 11 years. After multiple acute bouts, with symptom-free periods between them, the diagnosis of ARP was made. By the sixth episode, with Wirsung's duct irreversible changes on endoscopic ultrasound, the diagnosis of CP was presumed.

Despite the increasing incidence (or increased awareness) of $\mathrm{AP}$ in paediatric age, ${ }^{12}$ there is still limited literature regarding ARP and CP in children. ${ }^{3}$ CP remains an uncommon diagnosis in this age group, and there is no specific epidemiology available in paediatrics, despite two studies estimating low-incidence rates ranging from below $0.5 / 100000$ person-years in people younger than 20 years old to $0.5 / 100000$ person-years in children and young adults between 0 and 34 years old. In the second mentioned group, it has been estimated a prevalence of 10.3 per 100000 people. $^{45}$ Major risk factors identified for adult ARP and $\mathrm{CP}$ are rare in children, so data on the factors that predispose to progression from AP to ARP and $\mathrm{CP}$ in children was missing.

The INSPPIRE Consortium defined the concepts of AP, ARP and CP. The diagnosis of ARP requires the occurrence of two episodes of AP, in the absence of irreversible pancreatic structural changes, with a diseased-free period between the episodes. $\mathrm{AP}$ is defined by the presence of at least two of the following: characteristic abdominal pain; imaging consistent with AP; or lipase or amylase levels greater than three times the ULN. The diagnosis of CP requires the presence of irreversible, structural changes in the pancreas such as diffuse or focal destruction, sclerosis, pancreatic duct abnormalities/obstruction with at least one of the following: some periods of consistent abdominal pain or lipase or amylase levels greater than three times the ULN; exocrine pancreatic insufficiency; or endocrine pancreatic insufficiency. ${ }^{3}$

During the episodes of AP, the patient went through multiple etiological studies, including blood analyses, MRCP, investigation 
of celiac disease, cystic fibrosis, autoimmune diseases and other, all excluding non-genetic risk factors. After the sixth episode, he undergone an endoscopic ultrasound and an ERCP that revealed pancreatic structural changes, specifically encompassing the Wirsung duct and a genetic test was performed revealing a CFTR genetic variant.

The INSPPIRE group developed consensus relatively to the causal evaluation of ARP and CP. Accordingly, initial evaluation of ARP should include AST, ALT, GGT, total bilirubin, fasting lipids and total serum calcium. Patients with ARP also should have MRCP imaging of the pancreas. The search for a genetic cause of CP should include a sweat chloride test and mutation analysis of the genes mentioned above. ${ }^{6}$ MRCP should be used as the imaging method of choice, but if the likelihood of therapeutic intervention is high, ERCP is the best option. ${ }^{7}$

Recently, using INSPPIRE Consortium database, several risk factors were identified. The most commonly identified for children with $\mathrm{CP}$ were pancreatitis-predisposing genetic mutations (PRSS1-present in more than a half; SPINK1; CFTR; CTRC; CPA1). Other risk factors, in descending order of importance, include obstructive, toxic/metabolic, autoimmune causes. ${ }^{89}$

$\mathrm{CP}$ has an important negative impact on physical and mental quality of life. ${ }^{10}$ Children with severe abdominal pain, multiple ED visits, hospitalisations and consequently, missed days of school, experience an extreme disruption of normal childhood and education. Pain exacerbation and persistency also may lead to malnutrition, social deprivation, depression, analgesic dependence and other adverse effects. ${ }^{8}$ Over time, children with CP can develop exocrine pancreatic insufficiency and pancreatogenic diabetes mellitus. ${ }^{11}$

In this case, once the diagnosis of $\mathrm{CP}$ was established, successive therapeutic ERCP were planned and executed by an experienced adult gastroenterologist. The patient was also started on pancreatic enzyme replacement therapy (PERT) with pancreatin and nutritional support. Throughout the acute episodes the treatment was supportive, comprising intravenous hydration and analgesia.

For treating painful uncomplicated CP, the European Society of Gastrointestinal Endoscopy recommends ERCP as the firstline interventional option. ${ }^{12}$ In children, there is no single therapy that showed efficacy in stopping progression from ARP to CP. ${ }^{9}$ The main goal of medical management is to treat the complications of disease and to alleviate pain (acetaminophen and hydrocodone). Therapeutic ERCP is frequently utilised in children with CP and may offer benefit in selected cases, specifically if ductal obstruction is present. ${ }^{13}$ It proved to be a safe therapeutic option for pancreatic disorders in children when performed at centres with expertise. ${ }^{14}$ When all medical and endoscopic therapies fail to alleviate the pain and burden of CP, surgical interventions like cholecystectomy and total pancreatectomy or islet cell autotransplantation are considered. ${ }^{9}{ }^{15}$ PERT is indicated to correct exocrine pancreatic insufficiency and malnutrition in CP. Nutritional support must be provided. ${ }^{16}$

Subjects with a CFTR variant have increased risk of recurrent $\mathrm{AP}$ and $\mathrm{CP}$, which is associate with a significantly increased risk of pancreatic cancer but also male infertility and chronic sinusitis with minimal lung disease. The mortality rate compared with the general population is significantly increased in patients who develop pancreatic cancer, but does not appear to be increased in patients without pancreatic cancer. ${ }^{17}$

In the setting of a genetic mutation associated with hereditary pancreatitis, there are no clearly established methods of preventing development of disease, and so no family screening is indicated unless they develop symptoms. However, close relatives should be counselled to avoid environmental risk factors. ${ }^{17}$

\section{Patient's perspective}

Before the illness manifests itself, although it was some years ago, I remember feeling good and having a normal life. During hospitalisations and at the time of diagnosis, I remember suffering, of feeling exhausted and of not feeling well. Hospitalisations were always boring. After the ERCP's I feel much better, I still do not like being hospitalised to perform these procedures, but I hope not to suffer so much in the future.

\section{Learning points}

- The episodes of acute recurrent pancreatitis may be responsible for the development of chronic pancreatitis $(C P)$, since successive sudden events contribute to the development of irreversible ductal lesions, particularly stenoses, in the pancreatic canals, which fit the definition of $\mathrm{CP}$ making it important to reassess the clinical situation after each recurrence.

- $\mathrm{CP}$ is a rare diagnosis in childhood, and so it is necessary to recognise the lack of experience that paediatric specialists have in this area and to recognise the benefits of bringing together a multidisciplinary team including adult physicians in order to approach the patient.

- In addition to reducing the risk of life-threatening exacerbations, successful treatment of CP allows the patient to have a significant improvement in life quality, alleviating the daily symptoms that may have been present for years.

Contributors MPP contributed by discussing, planning, reporting and designing the case report and through acquisition of data. FS contributed by discussing, planning and conducting the clinical case. ASN contributed by planning, conducting, reporting and designing the clinical case. JC contributed by conducting, reporting and conceptioning the case and by analysing and interpretation data.

Funding The authors have not declared a specific grant for this research from any funding agency in the public, commercial or not-for-profit sectors.

Competing interests None declared.

Patient consent for publication Parental/guardian consent obtained. Provenance and peer review Not commissioned; externally peer reviewed.

ORCID iD

Miguel Paiva Pereira http://orcid.org/0000-0002-3783-6114

\section{REFERENCES}

1 Morinville VD, Barmada MM, Lowe ME. Increasing incidence of acute pancreatitis at an American pediatric tertiary care center: is greater awareness among physicians responsible? Pancreas 2010;39:5-8.

2 Nydegger A, Heine RG, Ranuh R, et al. Changing incidence of acute pancreatitis: 10 year experience at the Royal children's Hospital, Melbourne. J Gastroenterol Hepatol 2007;22:1313-6.

3 Morinville VD, Husain SZ, Bai H, et al. Definitions of pediatric pancreatitis and survey of present clinical practices. J Pediatr Gastroenterol Nutr 2012;55:261-5.

4 Dhiraj Y, Timmons L, Joanne TB, et al. Incidence, prevalence, and survival of chronic pancreatitis: a population-based study. Am J Gastroenterol 2011;106:2192-9.

5 Spanier BWM, Bruno MJ, Dijkgraaf MGW. Incidence and mortality of acute and chronic pancreatitis in the Netherlands: a nationwide record-linked cohort study for the years 1995-2005. World J Gastroenterol 2013;19:3018-26.

6 Gariepy CE, Heyman MB, Lowe ME, et al. Causal evaluation of acute recurrent and chronic pancreatitis in children: consensus from the INSPPIRE group. J Pediatr Gastroenterol Nutr 2017;64:95-103.

7 Kolodziejczyk E, Jurkiewicz E, Pertkiewicz J, et al. MRCP versus ERCP in the evaluation of chronic pancreatitis in children: which is the better choice? Pancreas 2016;45:1115-9. 
8 Schwarzenberg SJ, Bellin M, Husain SZ, et al. Pediatric Chronic Pancreatitis Is Associated with Genetic Risk Factors and Substantial Disease Burden.J Pediatr 2015;166:890-6.

9 Kumar S, Ooi CY, Werlin S, et al. Risk factors associated with pediatric acute recurrent and chronic pancreatitis. JAMA Pediatr 2016;170:562-9.

10 Amann ST, Yadav D, Barmada MM, et al. Physical and mental quality of life in chronic pancreatitis: a case-control study from the North American pancreatitis study 2 cohort. Pancreas 2013:42:293-300.

11 Aliye U, Douglas SF. Pancreatic disorders. Pediatr Clin N Am 2017;64:685-706.

12 Dumonceau J-M, Delhaye M, Tringali A, et al. Endoscopic treatment of chronic pancreatitis: European Society of gastrointestinal endoscopy (ESGE) clinical guideline. Endoscopy 2012;44:784-800.
13 David MT, Douglas SF, Bradley AB, et al. Therapeutic endoscopic retrograde cholangiopancreatography in pediatric patients with acute recurrent and chronic pancreatitis data from the INSPPIRE study. Pancreas 2017;46:764-9.

14 Agarwal J, Reddy DN, Talukdar R, et al. Ercp in the management of pancreatic diseases in children. Gastrointest Endosc 2014;79:271-8.

15 Abu-El-Haija M, Nathan JD. Pediatric chronic pancreatitis: updates in the 21st century. Pancreatology 2018;18:354-9.

16 Iglesia GD, Huang W, Szatmary P, et al. Efficacy of pancreatic enzyme replacement therapy in chronic pancreatitis: systematic review and meta-analysis. Gut 2017;66:1354-5.

17 Whitcomb DC. Hereditary pancreatitis.. In: Post TW, ed. UpToDate. Waltham, MA: UpToDate Inc, 2019. https://www.uptodate.com

Copyright 2019 BMJ Publishing Group. All rights reserved. For permission to reuse any of this content visit https://www.bmj.com/company/products-services/rights-and-licensing/permissions/

BMJ Case Report Fellows may re-use this article for personal use and teaching without any further permission.

Become a Fellow of BMJ Case Reports today and you can:

- Submit as many cases as you like

- Enjoy fast sympathetic peer review and rapid publication of accepted articles

- Access all the published articles

Re-use any of the published material for personal use and teaching without further permission

Customer Service

If you have any further queries about your subscription, please contact our customer services team on +44 (0) 2071111105 or via email at support@bmj.com.

Visit casereports.bmj.com for more articles like this and to become a Fellow 